\title{
Rectal Foreign Bodies in Older Men: a Novel Challenge and Humanistic Care for the Society
}

\author{
Zhenyu Yang \\ Tangdu Hospital, The Air Force Medical University \\ Peiyuan Xin \\ Tangdu Hospital, The Air Force Medical University \\ Tao Zhang \\ Tangdu Hospital, The Air Force Medical University \\ Chuxin Zhou \\ Tangdu Hospital, The Air Force Medical University \\ Xianli He \\ Tangdu Hospital, The Air Force Medical University \\ Guoqiang Bao ( $\sim$ guoqiang@fmmu.edu.cn ) \\ Tangdu Hospital, The Air Force Medical University
}

\section{Research Article}

Keywords: Rectal foreign bodies, Older men, Erotic purposes, Sexual behavior, Treatment

Posted Date: July 22nd, 2021

DOI: https://doi.org/10.21203/rs.3.rs-558553/v1

License: (c) (1) This work is licensed under a Creative Commons Attribution 4.0 International License. Read Full License 


\section{Abstract}

Background: In recent years, rectal foreign bodies are a common proctological emergency in the male population, especially in Chinese elderly men that often requires the intervention of the surgeon due to its complications. The aim of this review is to describe the epidemiology and clinical characteristics of rectal foreign bodies in elderly men and its possible challenge to clinicians and society.

Methods: A comprehensive literature search was conducted in English databases (PubMed, Embase, Web of Science, the Cochrane Library) and Chinese databases (CNKI, Wan Fang, VIP, Chinese biomedical database) from January 2000 to December 2020. All rectal foreign bodies relevant studies were considered, if they reported the purpose for a foreign body in the rectum and related treatment measures. Contemporaneous rectal foreign bodies cases data from our center were also analyzed. Two authors independently extracted the data and reviewed the quality of the included research. According to the differences in population background, we divided the elderly Chinese male group and the elderly non-Chinese male group, the parameters of the two groups were analyzed by statistical methods.

Results: A total of 159 literatures were preliminarily retrieved in initial literature search with rectal foreign body as the search term, including 86 Chinese literatures and 73 English literatures. A total of 582 patients were the elderly male patients, included 276 Chinese patients and 307 non-Chinese patients. In older men, the sources of foreign bodies can be divided into three categories: the ones that are inserted from the anus, the ones that are swallowed and thereafter become stuck in the rectum, the other that are caused by improper medical practices. The most common purpose for a foreign body in the rectum was insertion for erotic purposes. In the foreign body type, the daily articles account for the majority. Sexual articles are mainly found in pleasure seekers. There was no significant difference in foreign body sources, size, type, treatment selection and outcome between the two groups.

Conclusions: In older men, there is an increasing number of cases of rectal foreign body emergency visits for erotic purposes and sexual needs. Although the source, size and type of foreign body are different, and patients can get a better recovery after active and appropriate clinical treatment, the sexual needs are social problem we should pay attention to in older men. Treatment of sexual issues is a multidimensional task that should be implemented as a collaborative effort and older people should get more humanistic care in this regard.

\section{Introduction}

The aging of population has become one of the social concerned problems for all countries in the world. The global population, including the china, a developing country with the largest population base, is experiencing a demographic shift with the proportion of older adults (aged $\geq 60$ years) growing faster than any other age group(1). Older men, a major component of ageing population, have experienced changes in social and family roles and often face changes in psychological cognition. Additionally, Previous studies have often focused on empty-nesters, widowed elderly, psychological problems, elderly service team and other issues, while discussion about sexuality and intimacy, particularly in older adults, has been sparse(2).

Talking about sexuality in health care has slowly increased in recent years, along with the further improvement of social openness and cultural tolerance. people can get more sex knowledge through new media, which also caters to the understanding of the sexual needs of some elderly men. While it is generally assumed that sexuality diminishes with age, research studies suggest that sexual interest and activity lasts well into the eighth decade of life(3).

The elderly with superior economic conditions has met their low-level survival needs and do not need to consider basic life issues, so they have plenty of time to think about sex. The study pointed out that some older men do have sexual needs that are often ignored by society, and these older men's sexual needs are likely to have high-risk sexual behaviors under certain circumstances (4). There have been a few reports of retained rectal foreign bodies in older patients (6080 years old) who used them for self-treatment of faecal impaction or for prostate massage $(5,6)$.

Some older men address their sexual needs by trying a variety of different ways. For example, some elderly men try to get physical and psychological pleasure by inserting foreign objects into the anus, and there are also some elderly men who develop a sense of dependency after prostate massage due to chronic prostatitis (7). Therefore, more and more elderly male patients have been admitted to the hospital due to foreign bodies entering the rectum that cannot be removed by themselves(8). It has been reported in the literature that masturbation rectal foreign bodies tend to increase in recent years and have become the second cause of rectal foreign bodies(9). Also, according to the study, $75 \%$ of the cases of rectal foreign bodies were inserted into the rectum for erotic stimulation(8).

In recent years, more and more cases of rectal foreign bodies in elderly men have been admitted to our hospital. so, the following review is a summarizes of the relationship between rectal foreign bodies and sexual needs of elderly male patients. We attempted to arouse special social attention for this special group by to analyze the differences between elderly Chinese male patients and non-Chinese male patients with rectal foreign bodies and to analyze their sexual behavior needs and psychological characteristics.

\section{Methods}

\section{1 search strategy}

A comprehensive literature search was conducted in English databases (PubMed, Embase, Web of Science, the Cochrane Library) and Chinese databases (CNKI, Wan Fang, VIP, Chinese biomedical database) from January 2000 to December 2020. Search items were as follows: ("foreign bodies" OR "foreign matter") AND ("rectum" OR "anus"). Meanwhile, the clinical data of rectal foreign bodies cases in our hospital during the same period were also collected. 
The inclusion criteria should be as follows: 1). The eligible literature belongs to case report and clinical study. 2). The participants were male and older than 60 years. 3). The included patients had complete medical records.

The exclusion criteria should be as follows: 1). The same unit repeated the report; 2). The literature was meta-analysis related articles; 3 ). Misdiagnosed as rectal foreign body due to the disease itself, such as rectal tumor misdiagnosed as rectal foreign body.

\section{3 data extraction and outcome indicator}

The following data were extracted in EXCEL: 1). the first author, publication year, publication form, region, number of cases, 2). Patient characteristics, Foreign body sources, size, type, treatment selection and outcome.

\subsection{Ethical approval}

Written informed consent was obtained from all of study participants. This study was approved by the Ethics Committee of the Tangdu Hospital of Air Force Medical University (No.K202009-03) and conducted according to the standards of the Declaration of Helsinki.

\section{Results}

A total of 159 literatures were preliminarily retrieved in initial literature search with rectal foreign body as the search term, including 86 Chinese literatures and 73 English literatures. A total of 737 patients were retrieved, among whom 582 were male, accounting for $79 \%$. There were 276 Chinese patients, all of whom were male, and 461 non-Chinese patients, among whom 307 were male. The sources of foreign bodies can be divided into three categories: the ones that are inserted from the anus, the ones that are swallowed and thereafter become stuck in the rectum, the other that are caused by improper medical practices. Among them, the first categories are the group of objects that are inserted via the anus and accounted for the majority, while the second are the group of objects that become stuck in the rectum after swallowing and was more common in children under 10 years old and elderly female patients.one case was found to be iatrogenic.

The types of foreign bodies can be classified as daily necessities, food and sexual articles, among which daily articles account for the majority, mainly for pleasure seekers and partly for unexplained reasons. Sexual articles are mainly found in pleasure seekers. The largest foreign body size was a $77 \mathrm{~cm}$ long steel rod, and the smallest denture and vegetable residue (granuloma formation) could be seen.

The most common purpose for a foreign body in the rectum was insertion for erotic purposes, and occasionally there may be involuntary insertions. It should be noted that a small number of drug dealers are included. The characteristic of transoral foreign body is mostly edible prickly food;

The process for the identification and selection of the relevant literatures, according to the inclusion and exclusion criteria, is depicted in Fig. 1. After screening the titles or abstracts, and retrieving for full texts, the twenty studies that fulfilled the inclusion criteria were published between 2000 and 2020 , and 35 male patients were analyzed in this systematic review, included 20 Chinese patients with age range $(70.70 \pm 6.76)$ and 15 non-Chinese patients with age range(70.83 \pm 7.14$)$. All of the included literatures were available as fully published papers. The characteristics of the literatures included are shown in Table 1 .

Among the elderly Chinese patients, 3 cases rectal foreign bodies were swallowed, passed through the gastrointestinal track and held up in the rectum, including jujube stone, duck bone and fish bone, and 17 cases rectal foreign bodies were inserted through the anus. In the elderly Chinese patients, most of the foreign bodies were daily articles and sexual articles, but no iatrogenic rectal foreign bodies were found. Among the elderly non-Chinese patients, 1 case rectal foreign bodies were swallowed and 14 cases inserted rectal, most of which came from household articles, including screwdrivers and various bottles. There was no significant difference in foreign body source between the two groups (P区0.05) (Fig. 2a). Further analysis was made from the source of the foreign body. We found that the swallowed foreign bodies of both groups of elderly patients were mainly derived from sharp food, such as fish bones, while the inserted foreign bodies were mainly derived from daily necessities and the patients who use sexual objects are mainly elderly non-Chinese patients or those with a high degree of education.

We showed that in $60 \%$ of the elderly Chinese cases and in $66.7 \%$ of the elderly non-Chinese cases, the foreign bodies were inserted into the rectum for erotic stimulation and gratification (Fig. 2b). By analyzing the shape and texture of rectal foreign bodies in the two groups, blunt foreign bodies and non-fragile foreign bodies accounted for a higher proportion than counterparts (Fig. 2c/2d).

The method of retrieval and complications of various anorectal foreign bodies were further analyzed. In elderly Chinese patients, transanal removal under local anesthesia was the main method. Compared with elderly non-Chinese patients, most retained anorectal foreign bodies in elderly Chinese patients can be successfully removed transanally under appropriate local anesthesia and only a small proportion will require general anesthesia and abdominal operation, the difference is statistically significant $(p=0.036 / 0.028)$ (Fig. 2e/2f). While one elderly non-Chinese patient died because of the necrosis of intestinal mucosal tissue and systemic infection caused by a long time of treatment, there were no significant differences in the incidence of complications $(P=0.383)(F i g .2 g)$.

The data of a total of 8 patients, who received our hospital with complete data over 10 years, were prospectively recorded in Table 2. All patients had a median age of 58 years and included 2 female and 6 male patients. The purpose of inserting rectal foreign body was to stimulate erotic feeling in 5 male patients. 2 had vibrators (Fig. 3a/3b/3c), 1 had a can of portable toothbrush (Fig. 3d/3e), 1 had a ceramic drinking cup, 1 had a $30 \mathrm{~cm} \mathrm{long} \mathrm{bamboo} \mathrm{(Fig.} \mathrm{3f/3g).} \mathrm{All} \mathrm{of}$ these foreign bodies were cylindrically shaped objects. Other objects that were encountered included a piece of date pit that was stuck on the rectum wall in one 53 years female case (Fig. 3h), an intrauterine contraceptive device (IUCD) that migrated to the rectouterine space in one 57 years female case (Fig. 3i), Stapler residual nail that was remained in a 34-year-old male individual who had undergone hemorrhoids. 
The etiology of the foreign body in the rectum was erotic purposes in 5 elderly male patients, migration of an intrauterine device in one elderly female patient and accidents swallow in one female case. All patients in the erotic group were male and most of them live alone or are divorced.

The diagnosis was verified by ask the medical history, rectal examination and plain X-ray imaging in 5 patients who had foreign bodies in their rectum for erotic purposes. The patients who had a piece of date pit in their rectum presented with pelvic and perianal pain, which became exacerbated with defecation and diagnosed by anal fingering examination. The diagnosis was confirmed by anamnesis and plain X-ray imaging in one patient who had an intrauterine contraception device that had migrated to the rectum. The patient who had a stapler residual nail that presented pain in the stools was diagnosed during an anoscope examination.

In the process of clinical treatment, we successfully removed the foreign body of a patient whose rectum was inserted into a bamboo node about $30 \mathrm{~cm}$ long for sexual needs directly through surgical forceps and the patient's action of increasing abdominal pressure. The one erotic object could not be extracted even with laparotomy and bimanual maneuvers, and a colostomy was the selected method in this case, which was returned to colostomy 3 months after the operation without any complications. The other erotic object was extracted from 3 of the patients by rectoscopy or surgical forceps under spinal or general anesthesia performed in our general endoscope room. Extraction attempts to remove the foreign body with colonoscopy were successful in 3 of the patients. All patients recovered without any complications after aggressive clinical treatment.

\section{Discussion}

In the past, a large number of literatures have focused on the diagnosis and clinical diagnosis and treatment of rectal foreign bodies(10-15), while few articles have studied the psychological and sexual needs of elderly male patients from the perspective of rectal foreign bodies. In this paper, we have reviewed rectal foreign literatures and combined with rectal foreign cases in our center. The case information was statistically analyzed from aspects of patients' general characteristics, source of rectal foreign body, type of foreign body, size of foreign body, purpose of placement of foreign body, visiting time, treatment method, prognosis and outcome, and the difference between Chinese and non-Chinese patients with rectal foreign body and the proportion of elderly male patients in it were analyzed.

Based on comprehensive literature analysis, we found, on the one hand, due to different sizes, types and sources of foreign bodies, their clinical manifestations, clinical treatment methods and prognosis were also different according to the source of the foreign body. For example, oral rectal foreign bodies were mostly caused by ingestion, improper eating or overeating, resulting in the accumulation of foreign bodies in the ampullary of the rectum, or because the foreign bodies cannot be discharged after piercing the rectum wall. The volume of this kind foreign body was generally small, and most of the oral foreign body can be discharged from the anus after $4-5$ days $(16,17)$. However, if the oral rectal foreign body was generally $\geq 5 \mathrm{~cm}$ in circumference and $\geq 12 \mathrm{~cm}$ in length, hooked, barbed, sharp, polygonal or small and abundant, it was not easy to discharge, and often requires surgical intervention(18). The most common source of rectal foreign body was introduced through the anus, and this kind of rectal foreign body was mostly due to the patient's own to relieve anorectal symptoms or masturbation behavior after accidentally inserted but cannot be removed; Or the patients suffered an accidental injury and was forcibly inserted from the anal. The volume of this kind foreign body was generally large, and most of the anal rectal foreign body can cause patients abdominal pain, perianal pain, rectal bleeding or intestinal obstruction symptoms(9); Almost any conceivable object can be found in the rectum, including sex toys such as vibrators, batteries, light bulbs, candles, glass cups and wine bottles, metal, wooden objects, fruits and vegetables (such as cucumbers), aerosol cans and hats, illegal drugs, and unusually large objects such as soda or beer bottles(18-20); Rectal foreign bodies often cause mucosal edema, tearing and bleeding in the rectum and intestine wall. If these patients are not treated early, they often develop perforation and peritonitis, leading to shock symptoms.

On the other hand, although this type literature and the number of patients we included may be relatively small, we found that a large proportion of older male patients were sexually motivated, and this trend is increasing. And we also found that its various foreign body type often caused more serious clinical symptoms, brought great challenge to our clinical diagnosis and treatment(21). Therefore, we believe that caring for the sexual needs and sex lives of older people, especially older men, is also an issue facing our society that needs our adequate awareness and wide attention.

Based on the research of this paper, we believe that this study has two levels of significance. The first is its theoretical significance. At present, there are few studies on the survival status and sexual psychoanalysis of elderly men from the perspective of personal behavior in the academic circle, and even fewer studies on the analysis from the perspective of rectal foreign bodies. In this topic, we have reviewed and sorted out the academic achievements related to elderly men and rectal foreign bodies. On the basis of the analysis, induction and summary of these literatures, we have extracted the main viewpoints of caring for the human sexual needs and sexual psychology education of the elderly, and found the research gaps to provide ideas for further research(3). At the same time, we reported in the literature involved in senile behavior content as text and on the basis of the quantitative research to statistical analysis of the reports, which induces the cultural degree, survival status of the elderly may have relationship with rectal foreign body type. For example, we found that patients with rectal foreign bodies as sexual objects were mostly those with higher education or urban residents, while patients living in rural areas for a long time or widowed living alone had more rectal foreign bodies with their surrounding living utensils, and young patients were more likely to have a history of sexually transmitted diseases and homosexuality.

Secondly, it has practical significance: under the social background of accelerated aging in China, the image and demand of the elderly group are actually diverse. Elderly people not only need hobbies for leisure and physical maintenance, but also need emotional comfort and social participation. At present, there are more rural elderly people than urban ones in China. Due to the backward economy in rural areas, more lonely elderly people, lower level of knowledge, and incomplete social security, the elderly in rural areas have poorer material, spiritual and cultural living conditions than the elderly in urban areas, and the whole society pays less attention to them, especially for the less developed western areas of China. Lastly, Sexuality is a complex biopsychosocial and spiritual state of mind. Treatment of sexual issues is a multidimensional task that should be implemented as a collaborative effort(3). 


\section{Conclusions}

Therefore, for the elderly group, the physiological needs, like material needs and spiritual needs, need the attention of the society and media, especially the sexual psychological needs which are often ignored by us;

\section{Abbreviations}

IUCD: intrauterine contraceptive device;

\section{Declarations}

\section{Ethics approval and consent to participate}

Written informed consent was obtained from all of study participants. This study was approved by the Ethics Committee of the Tangdu Hospital of Air Force Medical University (No.K202009-03) and conducted according to the standards of the Declaration of Helsinki.

\section{Consent for publication}

Not applicable

\section{Availability of data and material}

Data can be obtained from the corresponding author upon reasonable request.

\section{Competing interests}

All authors have completed the ICMJE uniform disclosure form. The authors have no conflicts of interest to declare.

\section{Funding}

Not applicable

\section{Author Contributions Statement}

Guoqiang Bao and Xianli He designed and conceived the manuscript. Zhenyu Yang and Tao Zhang collected patient data and prepared all figures. Peiyuan Xin and Chuxin Zhou analyzed and interpreted the data. Zhenyu Yang and Peiyuan Xin wrote the main manuscript text. All authors reviewed the manuscript.

\section{Acknowledgments}

The authors appreciate the contributions of the patients who participated in this study.

\section{References}

1. Partridge L, Deelen J, Slagboom PE. Facing up to the global challenges of ageing. Nature. 2018;561(7721):45-56.

2. Katz A. The sounds of silence: sexuality information for cancer patients. J Clin Oncol. 2005;23(1):238-41.

3. Williams AC, Reckamp K, Freeman B, Sidhu R, Grant M. Sexuality, lung cancer, and the older adult: an unlikely trio? J Adv Pract Oncol. 2013;4(5):331-40.

4. Dhar HL. Gender, aging, health and society. J Assoc Physicians India. 2001;49:1012-20.

5. Goldberg JE, Steele SR. Rectal foreign bodies. Surg Clin North Am. 2010;90(1):173-84, Table of Contents.

6. Rodriguez-Hermosa JI, Codina-Cazador A, Ruiz B, Sirvent JM, Roig J, Farres R. Management of foreign bodies in the rectum. Colorectal Dis. 2007;9(6):5438.

7. Caliskan C, Makay O, Firat O, Can Karaca A, Akgun E, Korkut MA. Foreign bodies in the rectum: an analysis of 30 patients. Surg Today. 2011;41(6):795800.

8. Ayantunde AA. Approach to the diagnosis and management of retained rectal foreign bodies: clinical update. Tech Coloproctol. 2013;17(1):13-20.

9. Robertson WJ. 'Believe it or not': the medical framing of rectal foreign bodies. Cult Health Sex. 2017;19(8):815-28.

10. Wu JH, Zhang HY, Xia Y, Jiang LQ, Yuan Y, Xu SG, et al. A novel technique for minimally invasive removal of a foreign body in the rectal wall. Tech Coloproctol. 2018;22(4):313-7.

11. Bakheit IA, Elhasan GAB, Salih MA. A case of impacted foreign body in the rectum that was extracted using size 24 Foley catheter. Int J Surg Case Rep. 2020;66:146-8.

12. Bulte JP, Clermonts S, Zimmerman DDE. Antegrade impalement of the rectum by a foreign body: a case report of a successful transanal extraction using the transanal single port (TAMIS) technique. Tech Coloproctol. 2019;23(2):175-8.

13. Gajjar RA, Gupta PB. Foreign body in the rectum: A challenge for the emergency physician. J Family Med Prim Care. 2016;5(2):495-7.

14. Gentile M, Cestaro G, Di Filippo G, Amato B, Sivero L. Successful transanal removal of unusual foreign body self-inserted in the rectum A case report and review of literature. Ann Ital Chir. 2019;90:88-92. 
15. Jung EJ, Ryu CG, Kim G, Hwang DY. Impaction of a foreign body in the rectum by improper use of a (electronic) massager: a case report. J Korean Soc Coloproctol. 2010;26(4):298-301.

16. Sajjad H, Paish LM. Rectum Foreign Body Removal. StatPearls. Treasure Island (FL)2020.

17. Tatar C, Karsidag T, Hut A. Successful endoscopic removal of a foreign body in the rectum. Turk J Gastroenterol. 2014;25(4):442-3.

18. Ye H, Huang S, Zhou Q, Yu J, Xi C, Cao L, et al. Migration of a foreign body to the rectum: A case report and literature review. Medicine (Baltimore). 2018;97(28):e11512.

19. Narjis Y, Rabbani K, Hakkou K, Aboulhassan T, Louzi A, Benelkhayat R, et al. Foreign body of the rectum: An unusual case. J Emerg Trauma Shock. 2010;3(3):306.

20. Rodrigues GS, Lobo DN. A foreign body in the rectum. Indian J Surg. 2010;72(1):74.

21. Vahdati SS, Shahri SA, Habibollahi P, Sadigh SL. Medical image. Anal pain: think about foreign body in the rectum. N Z Med J. 2012;125(1356):96-9.

\section{Tables}


Table 1

General characteristics about the patient and foreign bodies and extraction method and complications

\begin{tabular}{|c|c|c|c|c|c|c|c|c|c|c|c|c|}
\hline Study & Year & cases & $\begin{array}{l}\text { Age } \\
\text { (year) }\end{array}$ & $\begin{array}{l}\text { Marital } \\
\text { status }\end{array}$ & Cause & $\begin{array}{l}\text { Medical } \\
\text { history }\end{array}$ & Source & $\begin{array}{l}\text { Foreign } \\
\text { body }\end{array}$ & Size(cm) & $\begin{array}{l}\text { Admission } \\
\text { time(h) }\end{array}$ & $\begin{array}{l}\text { Extraction } \\
\text { method }\end{array}$ & Complication \\
\hline $\begin{array}{l}\text { Peng et } \\
\text { al. }\end{array}$ & 2011 & 1 & 68 & NA & Erotic & Difficult & Anus & Bottle & $12 * 6 * 6$ & 36 & SA/TA & No \\
\hline \multirow[t]{3}{*}{$\begin{array}{l}\text { Wang et } \\
\text { al. }\end{array}$} & \multirow[t]{3}{*}{2000} & \multirow[t]{3}{*}{3} & 72 & Widowed & Erotic & Difficult & Anus & $\begin{array}{l}\text { Electric } \\
\text { bulb }\end{array}$ & $5 \star 3$ & 48 & SA/TA & No \\
\hline & & & 68 & Widowed & Erotic & Difficult & Anus & Bottle & $5 \star 2.5$ & 72 & SA/TA & No \\
\hline & & & 65 & Widowed & Erotic & Difficult & Anus & Rolling pin & $25 \star 2.5$ & 20 & SA/TA & No \\
\hline Xu et al. & 2001 & 1 & 72 & NA & Swallow & Easy & Oral & Date pit & 1 & 168 & NOA/TA & No \\
\hline $\begin{array}{l}\text { Shen et } \\
\text { al. }\end{array}$ & 2006 & 1 & 68 & NA & Treatment & NA & Anus & Bottle & 4 & 4 & SA/TA & No \\
\hline Li et al. & 2007 & 1 & 79 & NA & NA & NA & Anus & Bottle & 6 & 48 & GA/LA & No \\
\hline $\begin{array}{l}\text { Zeng et } \\
\text { al. }\end{array}$ & 2013 & 1 & 83 & NA & NA & Difficult & Anus & Bottle & NA & 2 & SA/TA & No \\
\hline Ma et al. & 2013 & 1 & 70 & Married & Treatment & General & Anus & $\begin{array}{l}\text { Prostate } \\
\text { massager }\end{array}$ & NA & 48 & $\begin{array}{l}\text { NOA/TA } \\
\text { (CO) }\end{array}$ & No \\
\hline $\begin{array}{l}\text { Zhang } \\
\text { et al. }\end{array}$ & 2002 & 1 & 65 & Widowed & Erotic & Difficult & Anus & flashlight & $9 * 3$ & 24 & NOA/TA & No \\
\hline $\begin{array}{l}\text { Yan et } \\
\text { al. }\end{array}$ & 2011 & 1 & 64 & Married & Erotic & Difficult & Anus & Bottle & $6 * 5$ & 168 & SA/TA & No \\
\hline $\begin{array}{l}\text { Deng et } \\
\text { al. }\end{array}$ & 2009 & 1 & 65 & NA & NA & NA & Anus & Bottle & $20 \star 5$ & 72 & SA/TA & No \\
\hline \multirow{3}{*}{$\begin{array}{l}\text { Guo et } \\
\text { al. }\end{array}$} & \multirow[t]{3}{*}{2003} & \multirow[t]{3}{*}{3} & 63 & NA & Erotic & Difficult & Anus & Bottle caps & $5 * 3$ & 112 & SA/TA & No \\
\hline & & & 84 & NA & Erotic & Difficult & Anus & Bottle caps & $5 \star 4 \star 3$ & 10 & SA/TA & No \\
\hline & & & 65 & NA & Erotic & Difficult & Anus & Screwdriver & $32 \star 15 \star 5$ & 3 & NOA/TA & No \\
\hline \multirow{2}{*}{$\begin{array}{l}\text { Han et } \\
\text { al. }\end{array}$} & \multirow[t]{2}{*}{2010} & \multirow[t]{2}{*}{2} & 64 & Single & Erotic & Difficult & Anus & Bottle & $18 * 3$ & $72 \mathrm{~h}$ & NOA/TA & No \\
\hline & & & 72 & Single & Erotic & Difficult & Anus & Battery & $3 * 1.5$ & $48 \mathrm{~h}$ & NOA/TA & No \\
\hline $\begin{array}{l}\text { Guo et } \\
\text { al. }\end{array}$ & 2007 & 1 & 69 & NA & Erotic & Difficult & Anus & Stick & $28 * 3.5$ & $72 \mathrm{~h}$ & $\begin{array}{l}\text { NOA/TA } \\
\text { (CO) }\end{array}$ & No \\
\hline Li et al & 2006 & 1 & 74 & NA & Swallow & NA & Oral & Duck bone & $3.5^{\star} 1.8$ & 168 & SA/TA & No \\
\hline $\begin{array}{l}\text { Mao et } \\
\text { al }\end{array}$ & 2020 & 1 & 72 & NA & Swallow & NA & Oral & Barb & 3.5 & 96 & SA/TA & No \\
\hline \multirow{10}{*}{$\begin{array}{l}\text { Caliskan } \\
\text { et al }\end{array}$} & \multirow[t]{10}{*}{2011} & \multirow[t]{10}{*}{10} & 65 & NA & Erotic & NA & Anus & Bottle & 8 & NA & GA/LA & NA \\
\hline & & & 73 & NA & Erotic & NA & Anus & Bottle & 20 & NA & GA/LA & NA \\
\hline & & & 79 & NA & Erotic & NA & Anus & $\begin{array}{l}\text { Chocolate } \\
\text { box }\end{array}$ & 3 & NA & NOA/TA & NA \\
\hline & & & 60 & NA & Erotic & NA & Anus & Bottle caps & 8 & NA & SA/TA & NA \\
\hline & & & 66 & NA & Erotic & NA & Anus & Vibrators & 4 & NA & SA/TA & NA \\
\hline & & & 64 & NA & Erotic & NA & Anus & Plastic pipe & 5 & NA & SA/TA & NA \\
\hline & & & 65 & NA & Erotic & NA & Anus & Salt box & 3 & NA & GA/LA & NA \\
\hline & & & 65 & NA & Erotic & NA & Anus & $\begin{array}{l}\text { Toothpick } \\
\text { box }\end{array}$ & 5 & NA & GA/LA & NA \\
\hline & & & 79 & NA & Erotic & NA & Anus & Eggplant & 10 & NA & Death & Death \\
\hline & & & 81 & NA & Erotic & NA & Anus & Bottle & 7 & NA & NOA/TA & No \\
\hline $\begin{array}{l}\text { Shimizu } \\
\text { et al }\end{array}$ & 2014 & 1 & 74 & NA & Swallow & NA & Oral & Barb & NA & 720 & GA/LA & Infection \\
\hline $\begin{array}{l}\text { Romera } \\
\text { et al }\end{array}$ & 2017 & 1 & 68 & NA & NA & NA & Anus & Screwdriver & NA & NA & SA/TA & No \\
\hline
\end{tabular}




\begin{tabular}{|c|c|c|c|c|c|c|c|c|c|c|c|c|}
\hline Study & Year & cases & $\begin{array}{l}\text { Age } \\
\text { (year) }\end{array}$ & $\begin{array}{l}\text { Marital } \\
\text { status }\end{array}$ & Cause & $\begin{array}{l}\text { Medical } \\
\text { history }\end{array}$ & Source & $\begin{array}{l}\text { Foreign } \\
\text { body }\end{array}$ & Size(cm) & $\begin{array}{l}\text { Admission } \\
\text { time(h) }\end{array}$ & $\begin{array}{l}\text { Extraction } \\
\text { method }\end{array}$ & Complication \\
\hline $\begin{array}{l}\text { Kumar } \\
\text { et al }\end{array}$ & 2001 & 1 & 69 & Married & treatment & NA & Medical & Toothbrush & NA & NA & NOA/TA & No \\
\hline \multirow{2}{*}{$\begin{array}{l}\text { Cawich } \\
\text { et al }\end{array}$} & \multirow[t]{2}{*}{2017} & \multirow[t]{2}{*}{2} & 83 & NA & Medical & NA & Medical & Pen*3 & NA & NA & GA/LA & No \\
\hline & & & 60 & NA & Violence & NA & Anus & Bottle & NA & NA & NOA/TA & No \\
\hline
\end{tabular}

Note: NA, not available; SA, with spinal anesthesia; NOA, No anesthesia; GA, general anesthesia; LA, laparotomy; TA, trans anal; CO, Colonoscopy;

Table 2

The detailed information of rectal foreign body cases recorded in our hospital

\begin{tabular}{|c|c|c|c|c|c|c|c|c|c|c|c|}
\hline Case & Gender & $\begin{array}{l}\text { Age } \\
\text { (years) }\end{array}$ & $\begin{array}{l}\text { Marital } \\
\text { status }\end{array}$ & Cause & $\begin{array}{l}\text { Medical } \\
\text { history }\end{array}$ & Source & $\begin{array}{l}\text { Foreign } \\
\text { body }\end{array}$ & Size(cm) & $\begin{array}{l}\text { Admission } \\
\text { time }\end{array}$ & $\begin{array}{l}\text { Extraction } \\
\text { method }\end{array}$ & Complications \\
\hline 1 & Male & 32 & Married & Treatment & Easy & Medical & $\begin{array}{l}\text { Stapling } \\
\text { nail }\end{array}$ & $2 * 1$ & $\begin{array}{l}1 \text { year after } \\
\text { surgery }\end{array}$ & $\mathrm{SA} / \mathrm{TA}(\mathrm{CO})$ & NO \\
\hline 2 & Male & 64 & Married & Erotic & Easy & Anus & $\begin{array}{l}\text { Portable } \\
\text { toothbrush }\end{array}$ & $20 \star 3.5$ & $18 \mathrm{~h}$ & NOA/TA(CO) & NO \\
\hline 3 & Male & 50 & Married & Erotic & Easy & Anus & $\begin{array}{l}\text { Ceramic } \\
\text { cup }\end{array}$ & 10 & $5 \mathrm{~h}$ & $\mathrm{GA} / \mathrm{LA}$ & NO \\
\hline 4 & Female & 53 & Married & Eating & Easy & Oral & Date pit & 2.5 & 2 year & $\mathrm{GA} / \mathrm{TA}$ & NO \\
\hline 5 & Male & 73 & Married & Erotic & Easy & Anus & Bamboo & $27 \star 5$ & $36 \mathrm{~h}$ & NOA/TA & NO \\
\hline 6 & Female & 57 & Married & Treatment & Easy & Medical & IUCD & $3 * 2$ & $\begin{array}{l}20 \text { years } \\
\text { after } \\
\text { surgery }\end{array}$ & $\mathrm{GA} / \mathrm{LA}$ & NO \\
\hline 7 & Male & 65 & Married & Erotic & Easy & Anus & Vibrator & $20 * 2$ & $24 \mathrm{~h}$ & NOA/TA(CO) & NO \\
\hline 8 & Male & 34 & Divorced & Erotic & Easy & Anus & Vibrator & $16 * 4$ & $18 \mathrm{~h}$ & NOA/TA(CO) & NO \\
\hline
\end{tabular}

\section{Figures}




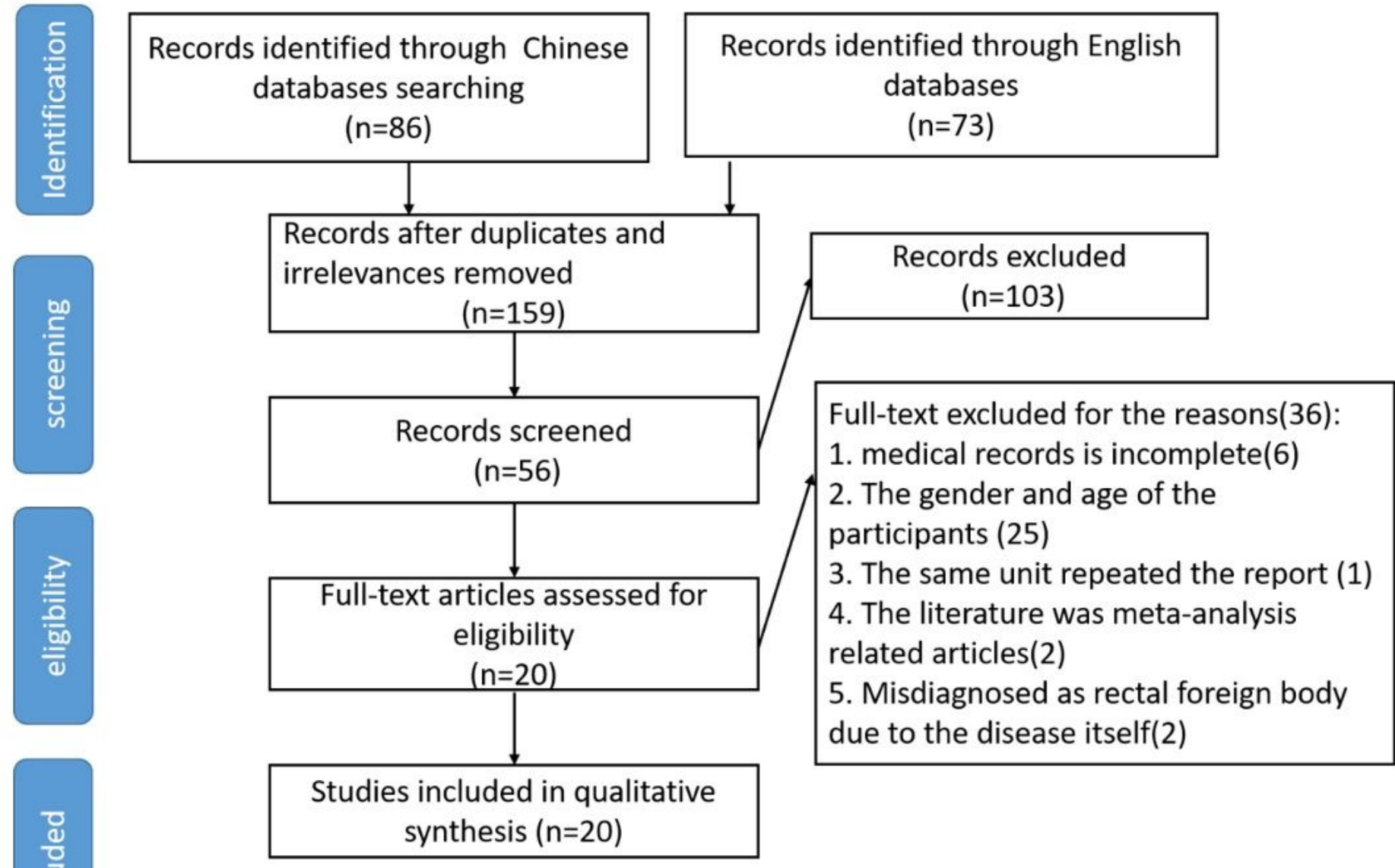

Figure 1

Flowchart of study inclusion 

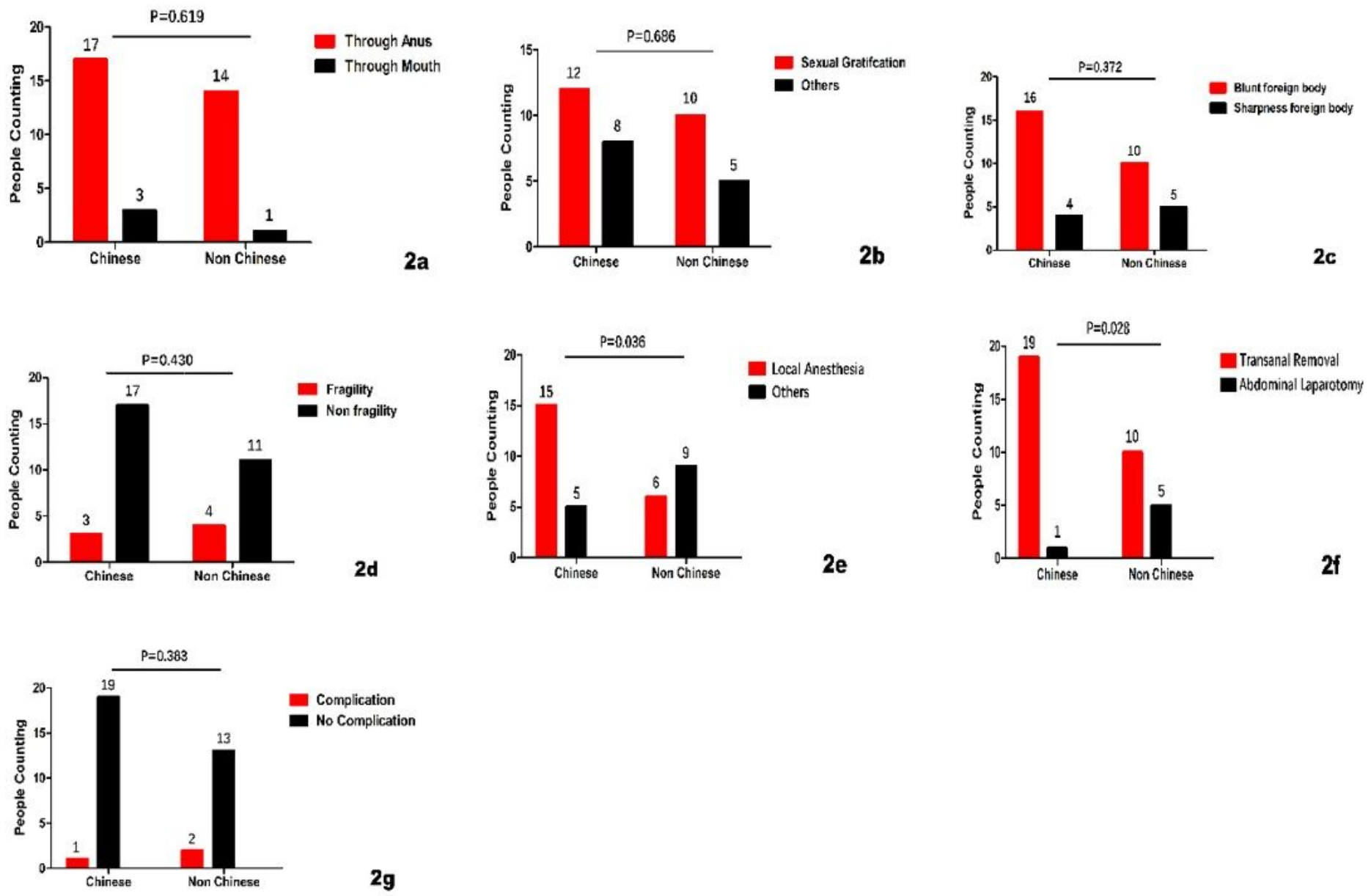

Figure 2

Comparison of basic information between Chinese elderly patients and non-Chinese elderly patients with rectal foreign body. Fig.2a: Comparison of sources of rectum foreign bodies between two groups; Fig.2b: Comparison of causes of rectum foreign body between two groups; Fig.2c/2d: Comparison of foreign body characteristics between two groups; Fig.2e/2f: Comparison of Extraction method of foreign body between two groups; Fig.2g: Comparison of postoperative complications between two groups of patients with rectal foreign body. 

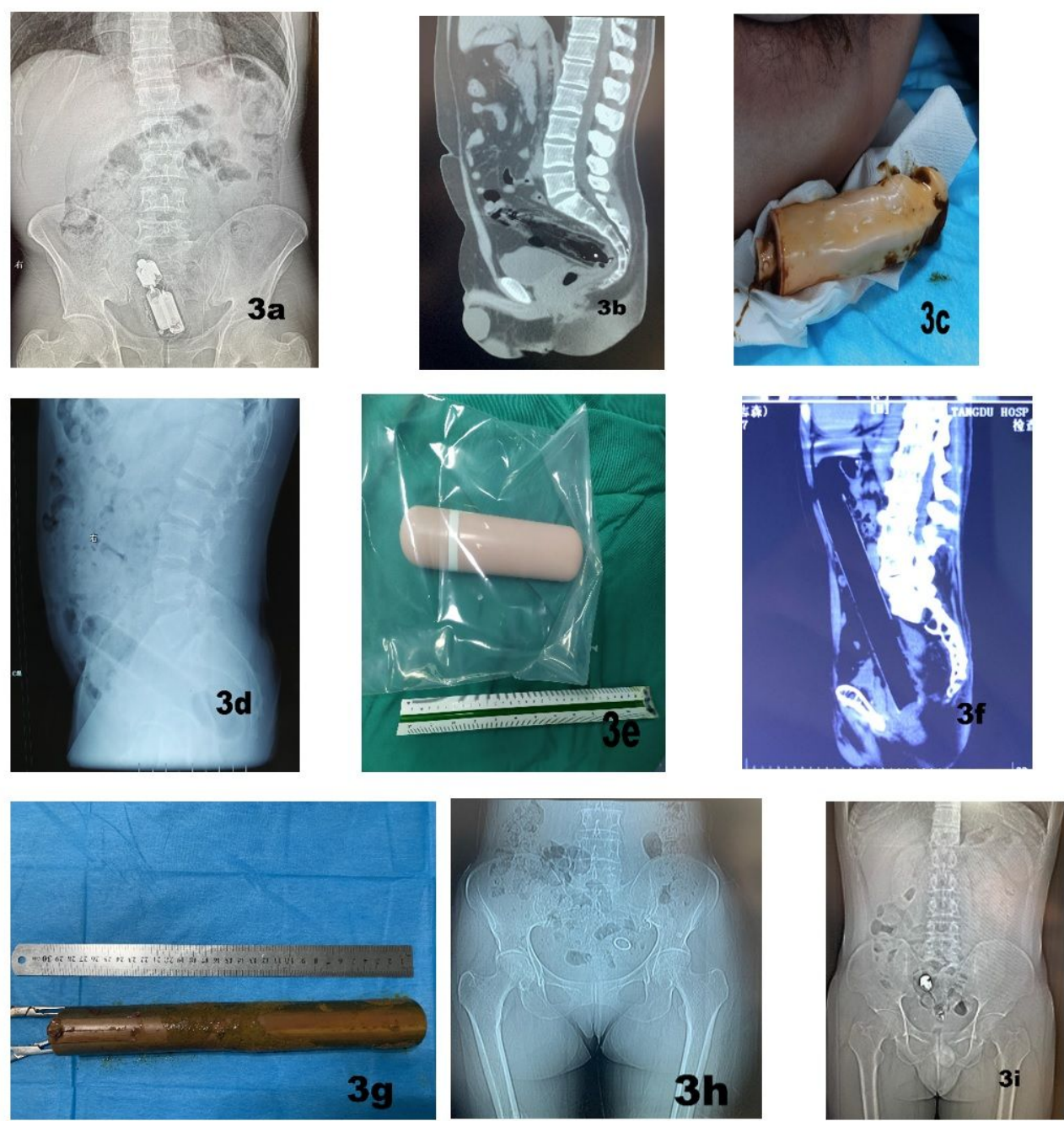

\section{Figure 3}

Rectal foreign body and its imaging pictures. Fig.3a/3b/3c: Vibrator images and physical object of two cases with rectal foreign body; Fig.3d/3e: portable toothbrush images and physical object of one case with rectal foreign body; Fig. $3 \mathrm{f} / 3 \mathrm{~g}$ : a $30 \mathrm{~cm}$ long bamboo image and physical object of one case with rectal foreign body; Fig.3h: a piece of date pit image that was stuck on the rectum wall in one 53 years female case; Fig.3i: IUCD image that migrated to the rectouterine space in one 57 years female case. 